\title{
PROCESSOS E PRÁTICAS SÓCIO-ESPACIAIS NO LOTEAMENTO SANTA TEREZINHA EM PORTO ALEGRE/RS
}

\author{
Processes and socio-espatial practices in the \\ Santa Terezinha neighborhood in Porto Alegre/RS \\ Procesos y prácticas socioespaciales en la parcelación \\ Santa Terezinha en Porto Alegre/RS \\ Emilio Luis Silva dos Santos* \\ Tânia Marques Strohaecker** \\ * Universidade Federal do Rio Grande do Sul (UFRGS) - emiliosilvasantos@gmail.com \\ ** Universidade Federal do Rio Grande do Sul (UFRGS) - tania.strohaecker@ufrgs.br \\ Recebido em 13/12/2019. Aceito para publicação em 04/03/2019. \\ Versão online publicada em 09/03/2020 (http://seer.ufrgs.br/paraonde)
}

\begin{abstract}
Resumo:
O objetivo desta pesquisa foi analisar os processos e as práticas sócioespaciais em um loteamento popular na área central de Porto Alegre/RS Loteamento Santa Terezinha (antiga Vila Central dos Papeleiros e Vila da Ponte), no bairro Floresta. A metodologia utilizada compreendeu entrevistas e trabalhos de campo. Para a análise dos dados, optou-se por uma adaptação do método conhecido como análise de conteúdo (BARDIN, 1979). Os resultados apontam para: ausência de liderança; resistência ao trabalho cooperativado formal; ausência/presença do Estado; pouca valorização da habitação/casa e; tráfico de drogas. Quando analisamos estas cinco características, identificamos uma dinâmica espacial peculiar que transita entre dois aspectos distintos: de um lado a aparente condição de permanência observada pela sociedade em geral, externa ao loteamento e, de outro lado, uma sutil mudança reconhecida por aqueles que trabalham diretamente com a população do Loteamento.
\end{abstract}

Palavras-chave: Vila dos Papeleiros; Produção do Espaço; Práticas SócioEspaciais.

\begin{abstract}
:
The goal of this research was to analyze socio-spatial processes and practices in a popular neighborhood in the central area of Porto Alegre/RS - Santa Terezinha Neighborhood (formerly known as Vila Central dos Papeleiros and Vila da Ponte), in the Floresta district. The methodology used comprised interviews and fieldwork. To analyze data, we chose an adaptation of a method known as content analysis (BARDIN, 1979). Results point out to lack of leadership; resistance to formal cooperative work; absence/presence of the State; lower home valuing; and drug trafficking. When we analyze these five points, we identify a peculiar spatial dynamics that moves around two distinct aspects: on one hand, the apparent condition of permanence observed by the society in general, external to the neighborhood, and on the other hand, a subtle change recognized by those who work directly with the neighborhood's population.
\end{abstract}

Keywords: Vila dos Papeleiros; Production of Space; Socio-Spatial Practices. 


\begin{abstract}
Resumen
El objetivo de esta investigación fue analizar los procesos y las prácticas socioespaciales en una parcelación popular en el área central de Porto Alegre/RS - Parcelación Santa Terezinha (antigua Vila Central dos Papeleiros y Vila da Ponte), en el barrio Floresta. La metodología utilizada comprendió entrevistas y trabajo de campo. Para el análisis de los datos, se optó por una adaptación del método conocido como análisis de contenido (BARDIN, 1979). Los resultados apuntan para: ausencia de liderazgo; resistencia al trabajo cooperativo formal; ausencia/presencia del Estado; poca valorización de la vivienda/hogar $\mathrm{y}$; narcotráfico. Cuando analizamos estos cinco rasgos, identificamos una dinámica espacial peculiar que transita entre dos aspectos distintos: por un lado, la aparente condición de permanencia observada por la sociedad en general, externa a la parcelación y, por otro lado, un sutil cambio reconocido por aquellos que trabajan directamente con la población de la Parcelación.
\end{abstract}

Palabras clave: Vila dos Papeleiros; Producción del Espacio; Prácticas Socioespaciales.

\title{
1. Introdução
}

Compreender a cidade atualmente é tarefa complexa que, em nossa opinião, se consubstancia na análise de duas questões primordiais: habitação e mobilidade. Estes dois elementos-chave da cidade moderna são discutidos à exaustão por planejadores, urbanistas, geógrafos e cientistas sociais na busca por formas e métodos de entender, explicar e propor a qualificação do espaço da cidade. Habitação e mobilidade estão intrinsecamente conectados, pois com o crescimento desordenado das cidades no Brasil a partir da segunda metade do século XX e da carência de políticas públicas eficientes, é cada vez mais difícil morar e deslocar-se na cidade principalmente para aquelas populações de mais baixa renda que não tendo esta condição facilitada tem que morar nas periferias distantes das áreas centrais onde, de modo geral, se concentra 0 emprego, tendo que enfrentar longas viagens desde a casa até o trabalho diariamente, dependendo de um transporte coletivo deficitário e oneroso.

Estas periferias geralmente são áreas impróprias para a habitação (áreas sujeitas a alagamentos e deslizamentos, margens de córregos) que não interessam ao mercado imobiliário seja pela distância em relação às áreas centrais, seja pelo alto custo de urbanização, o que, por oposição, torna as áreas centrais mais valorizadas; quanto mais próximo do centro maior é o valor, tanto de venda quanto de locação.

O processo de seletividade para a escolha do local de moradia pelos diferentes grupos sociais se modificou ao longo do tempo. Nos primórdios dos povoamentos humanos estes locais eram escolhidos pelas amenidades que apresentavam (proximidade de fontes de água e alimento, por exemplo). Atualmente, as amenidades são produzidas socialmente por diferentes agentes, entre eles, os promotores imobiliários, que elegem supostos benefícios deste ou daquele local específico (proximidade de equipamentos públicos, shopping centers, aeroportos, etc.). Aos grupos de baixa renda ou sem nenhuma renda não é dado o direito à seletividade, haja vista os locais onde a maioria destas comunidades habita. 
Aqueles que não têm a condição financeira para adquirir seu imóvel em bairros próximos à sua atividade laboral recorrem a loteamentos irregulares, clandestinos e a ocupações e, nos casos mais extremos, a opção que resta é morar na rua. A metrópole Porto Alegre/RS apresenta problemas de mobilidade e de habitação, no entanto, em áreas próximas ao centro histórico, que não enfrentam as dificuldades daquelas mais distantes e possuem infraestrutura implementada (energia elétrica, água, coleta de lixo, etc.), apresentam os mesmos problemas dos bairros e vilas periféricas como tráfico, violência policial, deterioração das habitações e do seu entorno. Buscando entender e explicar estas contradições presentes no espaço urbano da capital gaúcha, analisamos, neste trabalho, a dinâmica sócio-espacial da implementação de um condomínio de casas populares localizado na rua Voluntários da Pátria, próximo da estação rodoviária, região central de Porto Alegre, chamado de Loteamento Santa Terezinha.

O Loteamento foi construído entre os anos de 2005/2006 pela prefeitura municipal através de seu Departamento Municipal de Habitação (DEMHAB) e abriga uma população que trabalha principalmente, mas não unicamente, com a coleta, triagem e venda de materiais recicláveis. O local está, de modo geral, em precárias condições e sofre a ação continuada do tráfico de drogas. Assim, entendendo esta população como agentes transformadores do espaço vivido (definidos por Roberto Lobato Corrêa [2005] como grupo sociais excluídos), adequando-o ao seu modo de vida, nos questionamos: que processos/práticas sócio-espaciais estão presentes no Loteamento Santa Terezinha e que o (re)configuram ao longo do tempo?

$\mathrm{Na}$ busca por responder a estes questionamentos organizamos este trabalho com a seguinte estrutura: apresentamos uma abordagem sobre as práticas sócio-espaciais e o entendimento de vários autores sobre o tema, o que nos proporciona a base teórica para a discussão proposta. A seguir expomos o método e a operacionalização deste trabalho, descrevendo a forma como foi desenvolvida a pesquisa. No item seguinte traçamos um pequeno histórico do Loteamento Santa Terezinha, elencando os principais acontecimentos ao longo de sua existência. No item "resultado" são apresentados os dados compilados das entrevistas e que indicam possíveis respostas, mesmo que temporárias, aos nossos questionamentos $e$, finalmente nas considerações finais apresentamos nossa análise sobre o trabalho de pesquisa e possíveis encaminhamentos. A ilustração abaixo (Figura 1) apresenta a localização do Loteamento em relação ao município de Porto Alegre/RS. 
Figura 1 - Localização do Loteamento Santa Terezinha em Porto Alegre/RS.

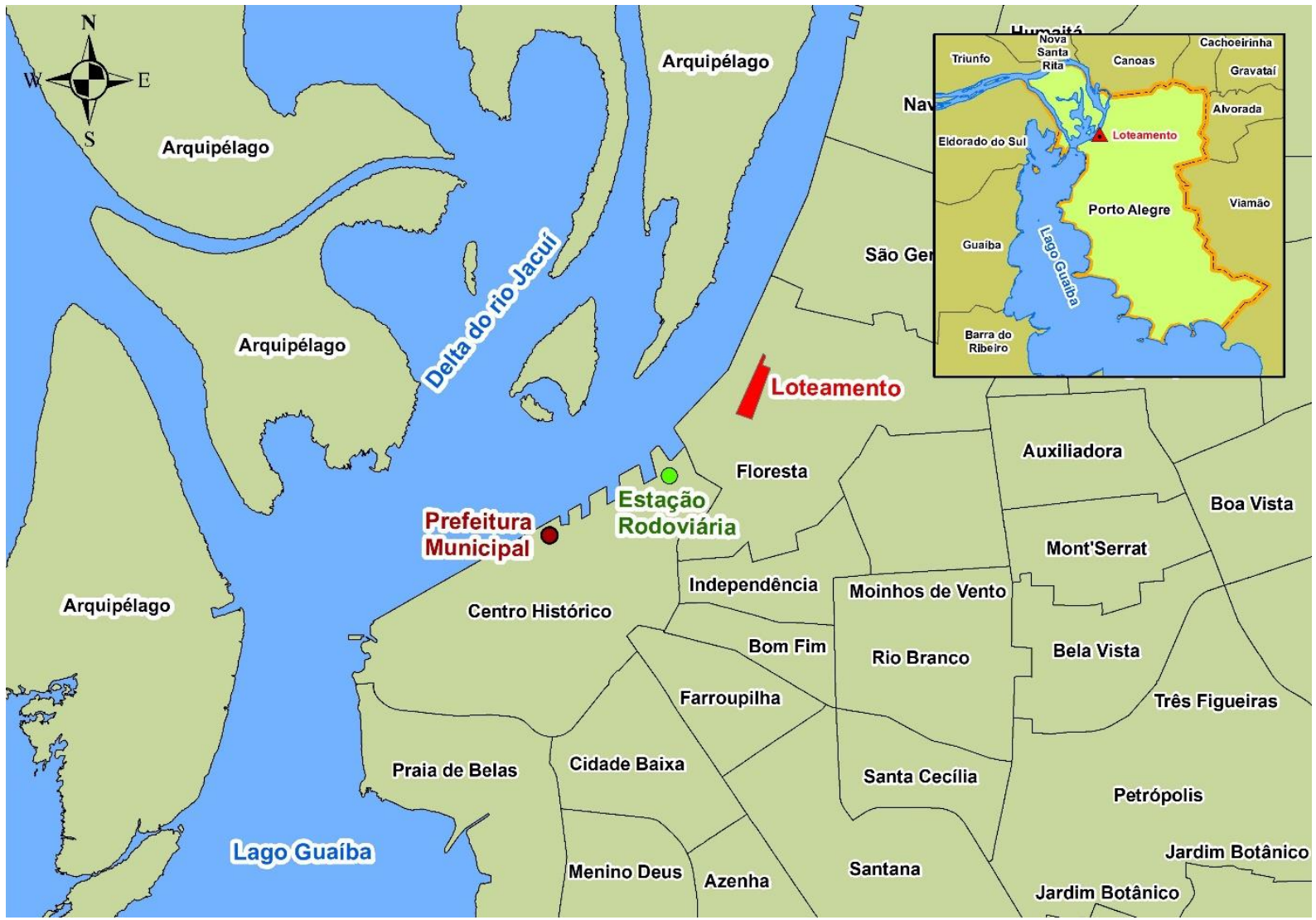

Fonte - O Autor, 2017.

\section{Práticas sócio-espaciais}

Marcelo Lopes de Souza argumenta que a prática espacial "nos aparece como algo dotado de certa particularidade, em grande parte como uma questão de perspectiva" (SOUZA, 2013, p.240). Para o autor, muito embora toda prática humana se dê no espaço sendo dele dependente, não é qualquer prática social que pode ser considerada prática espacial.

Estas práticas se apresentam de diversas maneiras variando ao longo do tempo com uma maior prevalência dada pelos grupos hegemônicos na sociedade, segundo Souza:

Elas têm servido, ao longo da história da humanidade, ora à dominação, à introdução e manutenção das hierarquias, à coerção e à imposição de cima para baixo ou de fora para dentro das leis e normas que regulam a vida de um grupo ou de uma sociedade [..] ora à emancipação, à autodeterminação e ao autogoverno, à autodefesa legítima, à instituição livre e legítima das leis e normas pelo próprio corpo de cidadãos diretamente. Em resumo: as práticas espaciais têm servido ora (e com muito mais frequência) à heteronomia, ora à autonomia ou, pelo menos, à luta contra a heteronomia. (SOUZA, 2013, p. 246-247)

Ana Fani Alessandri Carlos (2011) argumenta que a reprodução do espaço está intimamente ligada à reprodução das relações sociais, pois as relações 
sociais expressam-se no espaço de forma concreta:

Os sujeitos sociais que em suas necessidades e seus desejos vinculados à realização da vida humana, têm o espaço como condição, meio e produto de sua ação. Esses níveis correspondem àqueles da prática sócio-espacial real (objetiva e subjetivamente) que ganha sentido como produtora dos lugares, encerrando em sua natureza um conteúdo social dado pelas relações sociais que se realizam num espaço-tempo determinado, como um processo de produção, apropriação, reprodução da vida, da realidade e do espaço em seus descompassos, portanto fundamentalmente em suas contradições. (CARLOS, 2011, p.64)

As relações sociais sendo dialéticas e contraditórias em seus conteúdos, acabam por transformar o espaço, posto que este é o resultado concreto destas relações. As práticas espaciais organizam o espaço favorecendo àquelas classes dominantes e são, inclusive, reproduzidas pelos dominados em larga medida (SOUZA, 2013) revelando esta dialética. Para Christian Schmid, argumentando sobre a teoria de Lefebvre, o espaço é social, produzido pela sociedade, assim nos esclarece Schmid:

\begin{abstract}
Espaço (social) é um produto (social). Para entender esta tese fundamental, é necessário, antes de tudo, romper com a concepção generalizada de espaço imaginado como uma realidade material independente, que existe em "si mesma". Contra tal visão Lefebvre, utilizando-se do conceito de produção do espaço, propõe uma teoria que entende o espaço como fundamentalmente atado a realidade social - do que se conclui que o espaço "em si mesmo" jamais pode servir de ponto de partida epistemológico. O espaço não existe em "si mesmo". Ele é produzido. (SCHMID, 2012, p.91)
\end{abstract}

Corrêa define prática espacial como "um conjunto de ações espacialmente localizadas que impactam diretamente sobre o espaço" (CORRÊA, 2012, p.35). Segundo o autor, estas práticas podem ser meios de garantir apropriação de determinado território, valorizar ou desvalorizar alguma porção do espaço, atribuir significados que são constituintes da sociedade, ou seja, serve à produção, reprodução, manutenção, dissolução de determinadas formas e processos espaciais.

Assim, práticas espaciais e produção do espaço urbano estão intrinsecamente relacionadas. É através das práticas espaciais que se vai produzindo o espaço urbano sendo, ambas, condição e produto (CORRÊA, 2005) deste espaço, num constante (re)produzir-se. O Loteamento Santa Terezinha reproduz práticas espaciais que estão relacionadas à sua gênese, ainda que sua estrutura tenha se modificado, essas ações concretas configuram e reconfiguram este espaço procurando reiteradamente (através de processos) dar-lhe a forma e a função que desempenhava outrora.

\title{
3. Abordagem teórico metodológica e operacionalização da pesquisa
}

Devido à natureza desta pesquisa, que tem um caráter qualitativo, muito embora tenha dados quantitativos (que são complementares), optou-se por adotar uma adaptação do método conhecido como análise de conteúdo. 
Método sistematizado por Laurence Bardin (1979) que consiste em obter, a partir das informações anteriormente adquiridas nas entrevistas, significações que estão latentes, ou seja, que não estão explícitas em uma primeira análise. Segundo a definição de Bardin, entende-se análise de conteúdo como:

Um conjunto de técnicas de análise de comunicação visando a obter, por procedimentos sistemáticos e objetivos de descrição do conteúdo das mensagens, indicadores (quantitativos, ou não) que permitam a inferência de conhecimentos relativos às condições de produção/recepção destas mensagens. (BARDIN, 1979, p. 42)

Assim é possível, através da análise dos textos obtidos nas entrevistas, extrair significados implícitos. De acordo com Antonio Chizzotti:

A análise de conteúdo é uma dentre as diferentes formas de interpretar o conteúdo de um texto que se desenvolveu, adotando normas sistemáticas de extrair os significados temáticos ou os significantes lexicais, por meio dos elementos mais simples de um texto. Consiste em relacionar a frequência da citação de alguns temas, palavras ou ideias em um texto para medir o peso relativo atribuído a um determinado assunto pelo seu autor. (CHIZZOTTI, 2006, p.114)

Segundo Chizzotti (2006), este método parte do pressuposto de que as palavras ou a unidade lexical, o vocábulo, constitui-se em uma condensação da realidade do sujeito, e que a frequência de seu uso pode revelar, por exemplo, valores, crenças, etc. (CHIZZOTTI, 2006), assim é possível estabelecer-se conexões entre os vocábulos que sejam importantes à pesquisa. Como já se afirmou anteriormente, nossa proposta foi de uma adaptação deste método que utiliza, na sua elaboração formal, técnicas matemáticas e estatísticas que nesta pesquisa não constituem o objetivo principal.

Bardin (1979) argumenta que uma boa categorização deve conter determinadas qualidades, entre elas pode-se citar: exclusão mútua (um elemento não pode ser associado a duas categorias simultaneamente); homogeneidade (princípio único para cada categoria); pertinência (relação com o referencial teórico e os objetivos da pesquisa); objetividade e fidelidade (precisão na escolha das categorias) e produtividade (deve gerar novos conhecimentos, novas hipóteses).

\section{Segundo Rosana H. Câmara:}

Durante a interpretação dos dados, é preciso voltar atentamente aos marcos teóricos, pertinentes à investigação, pois eles dão 0 embasamento e as perspectivas significativas para o estudo. A relação entre os dados obtidos e a fundamentação teórica, é que dará sentido à interpretação. As interpretações a que levam as inferências serão sempre no sentido de buscar o que se esconde sob a aparente realidade, o que significa verdadeiramente o discurso enunciado, 0 que querem dizer, em profundidade, certas afirmações, aparentemente superficiais. (CÂMARA, 2013, p.189)

Estas interpretações se dão através do que Bardin (1979) chama de unidades de registro, que podem ser tanto palavras quanto frases que aparecem nos textos dos entrevistados e são consideradas unidades básicas 
de análise. Bardin conceitua unidade de registro:

\begin{abstract}
É a unidade de significação a codificar e corresponde ao segmento de conteúdo a considerar como unidade de base visando a categorização e a contagem frequencial. A unidade de registro pode ser de natureza e de dimensões muito variáveis. [...] todas as palavras do texto podem ser levadas em consideração ou podem reter-se unicamente às palavras-chave ou palavras-tema [...]. (BARDIN, 1979, p. 104-105)
\end{abstract}

A coleta dos dados envolveu o trabalho de campo, em que o pesquisador tem o contato direto com seu objeto de pesquisa e, neste caso, a comunidade alvo deste trabalho, o Loteamento Santa Terezinha em Porto Alegre/RS. Além disso, foi feito o tratamento dos dados obtidos com o trabalho de campo, que consistiu em separar os dados que são relevantes daqueles que não são. Para a coleta dos dados foi escolhida a técnica de entrevista, que Antonio Carlos Gil assim define:

\begin{abstract}
Pode-se definir entrevista como a técnica em que o investigador se apresenta frente ao investigado e lhe formula perguntas com 0 objetivo de obtenção dos dados que interessam à investigação. A entrevista é, portanto, uma forma de interação social. Mais especificamente, é uma forma de diálogo assimétrico, em que uma das partes busca coletar dados e a outra se apresenta como fonte de informação. (GIL, 1989, p.109)
\end{abstract}

Abaixo apresentamos um quadro referência (Quadro 1) com as datas das 30 entrevistas feitas ao longo da pesquisa.

Quadro 1 - Datas das entrevistas com moradores.

\begin{tabular}{cccc} 
Entrevista & Data & Dia da semana & Horário \\
$01 ; 02$ & $11 / 02 / 2017$ & Sábado & Entre 14:00 e 15:30 \\
$03 ; 04$ & $05 / 03 / 2017$ & Domingo & Entre 11:00 e 12:00 \\
05;06;07;08 & $11 / 03 / 2017$ & Sábado & Entre 14:30 e 16:00 \\
\hline $09 ; 10 ; 11 ; 12$ & $25 / 03 / 2017$ & Sábado & Entre 14:30 e 16:30 \\
\hline $13 ; 14 ; 15 ; 16$ & $08 / 04 / 2017$ & Sábado & Entre 10:30 e 12:30 \\
\hline $17 ; 18 ; 19 ; 20$ & $07 / 05 / 2017$ & Domingo & Entre 10:00 e 12:00 \\
\hline $21 ; 22$ & $10 / 05 / 2017$ & Quarta-feira & Entre 11:00 e 12:00 \\
\hline $23 ; 24 ; 25$ & $24 / 05 / 2017$ & Quarta-feira & Entre 10:00 e 11:30 \\
\hline $26 ; 27 ; 28$ & $04 / 06 / 2017$ & Domingo & Entre 10:20 e 11:30 \\
$29 ; 30$ & $09 / 06 / 2017$ & Sexta-feira & Entre 10:30 e 11:30
\end{tabular}

Fonte - O autor, 2017.

O modelo de entrevista proposto para esta pesquisa foi o semiestruturado, pois permite uma flexibilidade maior em relação às respostas do entrevistado, ao contrário da entrevista estruturada, onde prevalecem questões fechadas e que dão muito pouca margem para as respostas, já que prevê alternativas previamente estabelecidas às perguntas formuladas. Foram propostas cinco entrevistas não estruturadas com os agentes externos ao Loteamento, objetivando cobrir aqueles que têm uma relação mais próxima e atuam de forma continuada no Loteamento, tais como o DEMHAB, Serviço de Assistência Sócio Educativa (SASE), Centro de Saúde Santa Marta, Creche 
Menino Jesus e a paróquia Santa Terezinha. Não foi possível realizar todas as entrevistas propostas. O DEMHAB não respondeu à nossa solicitação para uma entrevista com assistentes sociais e, portanto, realizamos quatro entrevistas com técnicos externos.

A partir da definição das unidades de registro foi possível, além de todo o restante do processo de interpretação dos dados, chegar-se a algumas conclusões a respeito dos processos e práticas espaciais no Loteamento, frisando sempre que pela natureza da pesquisa (qualitativa), não existe uma rigidez nas conclusões, já que as respostas serão sempre parciais e influenciadas pela visão e pelo referencial teórico escolhido pelo pesquisador.

\section{Da vila ao loteamento: a gênese de um condomínio popular}

A gênese do Loteamento se dá no início dos anos de 1980 com um aglomerado de moradias precárias que vai se formando sob a Avenida Castelo Branco, chamada por seus moradores de Vila da Ponte. Este aglomerado de casebres se expande para uma área adjacente que também já possuía alguns casebres, formando o que se chamou na época de Vila Central dos Papeleiros devido às atividades desenvolvidas por seus moradores, basicamente a coleta, triagem e venda de papel, papelão e metais. A figura 2, a seguir apresenta uma imagem aérea do Loteamento.

\section{Figura 2- Imagem aérea do Loteamento Santa Terezinha, Porto Alegre/RS.}

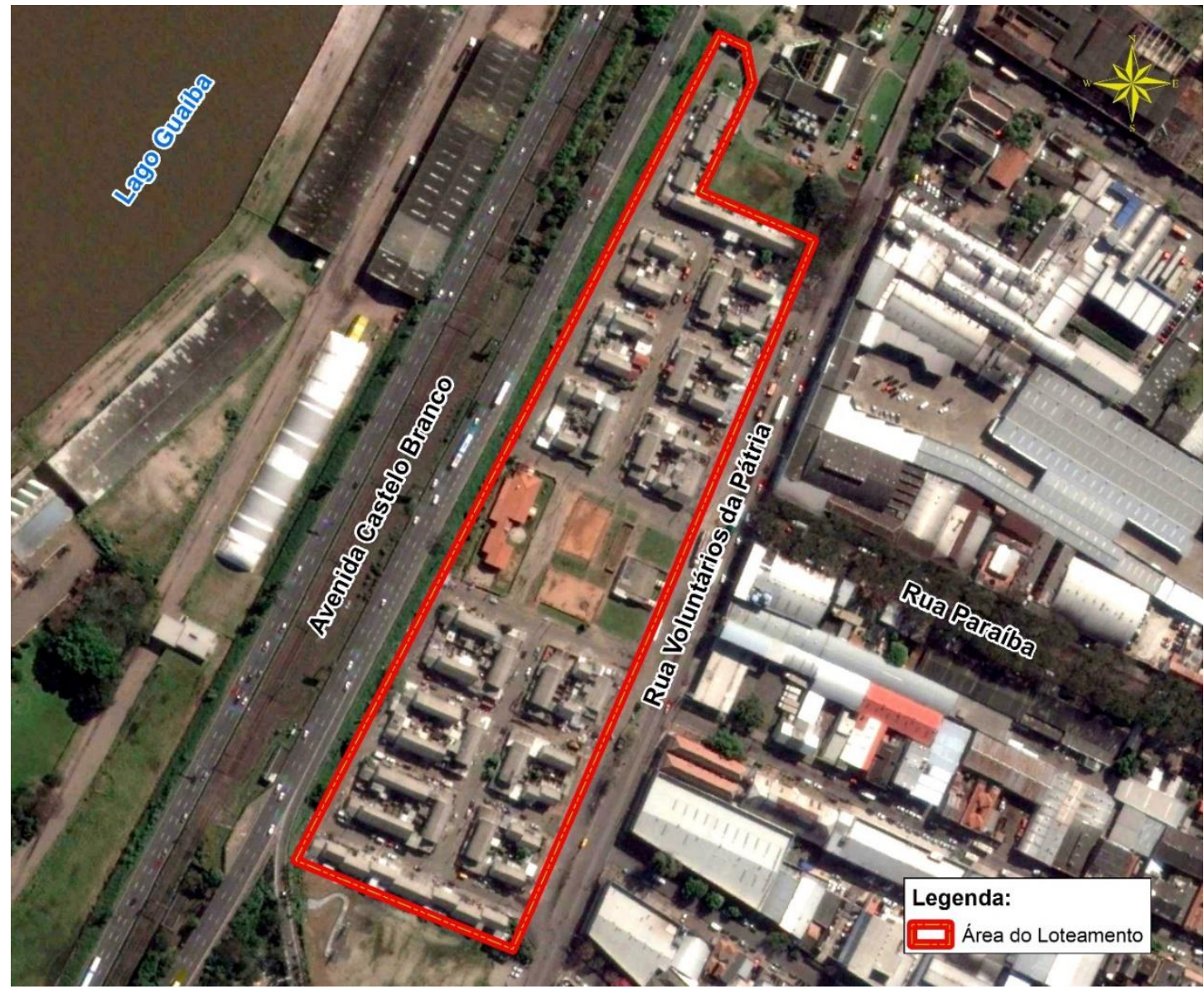

Fonte - Imagem Google Earth, 2017. Elaboração: Emilio Santos 2017. 
Vivendo em um ambiente totalmente insalubre, estas pessoas estavam expostas diuturnamente a diversas doenças e ao convívio com vetores patogênicos como ratos e ratazanas (problema citado por vários entrevistados durante a pesquisa). A maioria dos moradores da Vila é composta de carrinheiros (aqueles que puxam os carrinhos pela cidade no trabalho de coleta) e triadores (aqueles que separam os materiais após a coleta). Eles utilizam as próprias moradias como depósito e local de separação dos materiais. Além disso, havia aglomeração de pessoas em habitações precárias, ligações elétricas clandestinas utilizando fios elétricos sem isolamento necessário e utilizando material elétrico reaproveitado de bitolas (diâmetros) diferentes, que favoreciam acidentes como os incêndios, por exemplo.

Os moradores faziam a triagem dos materiais em suas próprias casas ou barracos e nas áreas adjacentes e aquilo que não era aproveitado era abandonado no entorno, o que transformou o lugar em um enorme depósito de materiais altamente inflamáveis. Uma estratégia muito usada pelos recicladores é o de atear fogo nos fios elétricos para remover o isolamento plástico, que não Ihes interessa, e assim ficar apenas com o cobre, material de alto valor de revenda. Este procedimento é apontado como uma das causas de incêndios que periodicamente ocorriam na Vila.

A primeira década dos anos 2000 foi de intensas mudanças para os moradores da Vila. Entre estas mudanças está a elaboração do Programa Integrado Entrada da Cidade (PIEC) pelo executivo municipal através do DEMHAB, cujo objetivo era a reestruturação urbana e a recuperação ambiental do acesso norte da capital abrangendo os bairros Anchieta, Humaitá, Farrapos, Navegantes e parte do bairro Marcílio Dias, onde estava localizada a Vila. As melhorias incluíam a construção de novas casas e a urbanização do lugar (arruamento, redes de energia elétrica e saneamento). Um momento significativo foi a assinatura do decreto no 14148 de 27 de março de 2003, que transformou a área onde estava localizada a Vila em Área Especial de Interesse Social (AEIS), acabando com a irregularidade e trazendo uma segurança jurídica aos moradores.

Além destes fatos, dois grandes incêndios ocorreram na Vila, um em março de 2004 e o outro em fevereiro de 2005, ambos noticiados nos jornais da cidade e tendo como prováveis causas as ligações elétricas clandestinas, a quantidade enorme de material inflamável em um mesmo local e a forma descuidada com que os moradores trabalhavam na triagem dos materiais recicláveis.

As primeiras unidades do Loteamento Santa Terezinha (doravante Loteamento) são entregues em dezembro de 2006 e em junho de 2008 são encerradas as obras das últimas casas totalizando 277 unidades habitacionais. É importante salientar que no Loteamento não estão somente os moradores da antiga Vila, foram reassentados lá também alguns moradores da Vila A. J. Renner, localizada no bairro Humaitá. Conforme notícia publicada no Diário Oficial de Porto Alegre (DOPA) do dia 18 de outubro de 2007, eram trinta famílias que viviam em situação precária na referida vila e que foram transferidas para o Loteamento. Segundo publicação do DEMHAB (2007),

ParaOnde!?, Porto Alegre, v.13, n.1, p.111-131, 2020. http://seer.ufrgs.br/paraonde 
estas pessoas não eram papeleiros, mas trabalhavam na construção civil e faziam serviços diversos, popularmente conhecido como "biscate".

Para além das mazelas diárias que os moradores enfrentam, existe a situação presente do tráfico de drogas no Loteamento. Periodicamente os jornais locais noticiam operações policiais com fins de prisão de traficantes e apreensão de drogas e armas. Não bastasse a situação de extrema carência em que vive grande parte dos moradores do Loteamento, estas reportagens agravam a situação, pois apresentam abordagens preconceituosas, equivocadas e estigmatizantes. As reportagens situam a operação da polícia na Vila dos Papeleiros, indicando que se localiza na parte sul do Loteamento. Além disso, passa a impressão de que todos que ali vivem são usuários ou traficantes de drogas, por isso equivocadas e preconceituosas. Estigmatizantes, pois imputam um estigma nos moradores que já possuem uma baixa autoestima por sua própria condição de vida.

Os moradores do Loteamento convivem diuturnamente com o tráfico e suas práticas espaciais tem que levar em consideração esta relação que lhes é imposta, tanto pelo traficante (lei do silêncio) quanto pela polícia (repressão). Como, em nossa opinião, não existe um planejamento de fato, mas apenas gestão, o Estado acaba por atuar de forma a apenas coibir o tráfico, situação que não é exclusiva do Loteamento, mas está presente em diversas vilas e bairros da capital gaúcha. A falta de um planejamento a longo prazo para a cidade se reflete nestas ações de cunho unicamente repressor e que não tem resultado prático, pois o tráfico continua atuante no Loteamento. É necessária a busca por alternativas que possam melhorar a condição de vida destes moradores e que esta mudança possa ser evidenciada, por exemplo, na alteração do perfil socioeconômico dos moradores, pois atualmente o que existe é uma condição de grande carência (instrução, habitação, perspectiva de trabalho).

\section{Resultados}

Considerando o antes exposto, apresentamos as unidades de registro que foram levantadas nas entrevistas e que, na nossa análise, podem responder aos questionamentos: ausência de liderança no Loteamento; resistência ao cooperativismo; ausência/presença do Estado; pouca valorização da habitação/casa e; presença do tráfico de drogas.

A ausência de liderança no Loteamento foi a primeira unidade de registro a surgir durante a análise do conteúdo das entrevistas. Dentre as diversas perguntas feitas aos moradores entrevistados, uma delas dizia respeito justamente à atuação de lideranças dentro do Loteamento para resolver conflitos internos e de intermediar negociações com os agentes públicos por conta de regularização de documentação de imóvel, serviços de infraestrutura das casas e da área do Loteamento, por exemplo.

Nas entrevistas realizadas, quando perguntados sobre quem procuravam quando alguma demanda surgia, todos, sem exceção, responderam que cada um resolvia o problema por sua própria conta e risco. Em nenhum momento foi citado o nome de alguém que pudesse ter este papel de liderança. Esta lacuna

ParaOnde!?, Porto Alegre, v.13, n.1, p.111-131, 2020. http://seer.ufrgs.br/paraonde 
na liderança da comunidade impede alguns avanços na qualidade de vida dos moradores. É necessário um maior engajamento da comunidade, uma associação de moradores mais ativa e atuante, que participe de forma continuada nos diversos conselhos municipais, por exemplo. Para que isso ocorra é necessária uma liderança que seja capaz de agregar pessoas, que seja capaz de motivá-las.

De acordo com as agentes de saúde, os moradores do Loteamento não têm motivação suficiente para participar, de forma constante, de trabalhos voluntários (participar de reuniões, comitês, associações, etc.). "Vão em uma reunião e depois não aparecem mais", elas relatam que mesmo tratando-se de formação de grupos que discutam sobre a saúde da mulher (doenças sexualmente transmissíveis, métodos anticonceptivos, etc.), é muito difícil a participação das mulheres da comunidade. Deste modo, entendemos que a ausência de uma liderança no Loteamento aparece como um fator que contribui para a manutenção da situação atual.

Outra unidade de registro que foi levantada durante as entrevistas, e que parece ser unânime entre os entrevistados, é uma certa resistência ao cooperativismo. A maioria dos moradores entrevistados se declararam recicladores, e apenas 02 deles trabalham em uma cooperativa (Cooperativa Mãos Unidas Santa Teresinha). A Cooperativa iniciou seus trabalhos em agosto de 2014 e sua criação se deu em função do Programa Todos Somos Porto Alegre, proposto pela prefeitura municipal. Fizemos uma visita a esta cooperativa para entrevistar duas moradoras do Loteamento que lá trabalham.

Como na maioria dos trabalhos formais, existem certas regras para 0 funcionamento da cooperativa, entre eles está o cumprimento de horários e uma certa conduta pessoal relacionada ao consumo de álcool e drogas no horário de trabalho. Esta disciplina requerida por parte dos coordenadores da cooperativa aos recicladores do Loteamento, acaba por afastá-los deste trabalho formal, principalmente os homens.

Outro motivo alegado pelos entrevistados é a baixa remuneração paga aos cooperativados e a forma de pagamento (a cada 15 dias), quando o trabalho na rua permite que ele venda, ao final do dia, seu material coletado a qualquer um dos compradores (aquele que tiver o melhor preço) de material reciclado espalhados pelas redondezas do Loteamento. Além disso, nas rotas que percorre durante o dia, ele tem a possibilidade de angariar doações de roupas, calçados, alimentos e até dinheiro, complementando assim sua renda.

O que eles alegam é que trabalhando dentro do galpão não há esta possibilidade. A prestação de contas da cooperativa também é motivo de desconfiança por parte dos entrevistados, alguns afirmam não haver clareza quanto aos lucros, às despesas e à distribuição dos rendimentos a cada um dos cooperativados. Outro aspecto apontado pelos entrevistados é o fato de que a coleta seletiva - feita por uma empresa terceirizada, contratada pelo Departamento Municipal de Limpeza Urbana (DMLU) - deveria levar aos galpões o material para ser triado e vendido, mas segundo eles o que chega no galpão é material ruim, o material que tem maior valor de revenda "já ficou pelo caminho", segundo um dos moradores entrevistados.

Para0nde!?, Porto Alegre, v.13, n.1, p.111-131, 2020. http://seer.ufrgs.br/paraonde 
Quando somamos a baixa remuneração, a mínima disciplina exigida para o trabalho, a desconfiança em relação às finanças e à coleta seletiva, o resultado é o completo desinteresse pelo programa Todos Somos Porto Alegre e pelo trabalho cooperativado em geral no Loteamento. Assim entendemos, através desta unidade de registro levantada nas entrevistas, que a situação de trabalho destas pessoas que vem desde os anos de 1980 na Vila dos Papeleiros é uma prática espacial que se reproduz e muito pouca alteração teve ao longo do tempo.

A resistência ao trabalho cooperativado formal encontra eco na desconfiança generalizada quanto à lisura da prestação de contas (contas a pagar, contas a receber, distribuição de lucros) e na baixa remuneração obtida. Para que se constitua uma cooperativa é necessária toda sorte de documentos, certidões, registros e pelo menos, vinte pessoas. Com o baixo nível de instrução aliada à falta de conhecimento técnico, a possibilidade de que a cooperativa não chegue a termo é grande. Assim, prática comum, as casas destas pessoas se transformam em área de triagem (onde separam os diversos materiais coletados) e depósito (aguardando que uma quantidade considerável seja obtida para a venda posterior), os materiais não aproveitados são dispensados no próprio local e, muitas vezes, nas calçadas e ruas do Loteamento, dando a impressão àqueles que por ali cruzam, seja de ônibus, automóvel, trem ou mesmo a pé que o Loteamento é um grande depósito de lixo.

Outra unidade de registro que ficou clara durante as entrevistas é a ausência/presença do Estado. Nos relatos dos entrevistados, quando perguntados sobre como era a relação com as diversas secretarias, empresas e autarquias da prefeitura, a resposta, de modo geral, era a mesma: "Eles aparecem aqui só prá cobrá"; "A gente aqui tá abandonado". A única secretaria elogiada foi a de saúde, por conta do ótimo trabalho, segundo os moradores, realizado pelas agentes de saúde da família do Centro de Saúde Santa Marta. Esta ausência referida pelos entrevistados tem relação com a ideia do Estado como provedor das necessidades da população. O entendimento expresso pelas opiniões dadas durante as entrevistas revela que, para eles, o Estado deve ser o agente provedor.

De outro lado, tem-se a presença do Estado como agente opressor, segundo os entrevistados, representado pela Brigada Militar e Polícia Civil, em grandes operações para o combate ao tráfico de drogas no Loteamento, noticiadas com frequência pelos meios de comunicação de massa. Segundo os moradores, nessas operações é comum a truculência policial: "Eles pedala a porta e vão entrando".

Esta relação contraditória com o Estado, de um lado referindo-se a ele como ausente de suas obrigações para com a população e de outro como o opressor que invade suas casas e os submete a constrangimentos, muito embora os traficantes também o façam, existe desde a formação da Vila dos Papeleiros e continua presente até os dias atuais. Assim, para estas pessoas o Estado aparece como dualidade: o que provê - este eu quero que esteja presente; e o que oprime - este eu quero que se mantenha afastado.

Considerando que, no entendimento dos entrevistados, o Estado aparece

ParaOnde!?, Porto Alegre, v.13, n.1, p.111-131, 2020. http://seer.ufrgs.br/paraonde 
muito mais como opressor, condicionando a intervenção a determinados comportamentos e hábitos dos moradores e muito menos como provedor das suas necessidades imediatas, é possível afirmar-se que esta tensão permanente entre o "nós" (moradores) e os "outros" (Estado) transforma o espaço do Loteamento, na medida em que impõe a eles uma condição de abandono nas questões sociais e, ao mesmo tempo, os coloca em uma condição de irregularidade e até mesmo de criminalidade por conta do tráfico de drogas.

Considerando-se que a maioria dos entrevistados tem mais de 50 anos, tem apenas 0 ensino fundamental incompleto (portanto baixa qualificação profissional) e que vivem na área do Loteamento há mais de vinte anos, é lícito inferir que estas pessoas já passaram por diversas administrações municipais que tiveram algum tipo de ação no Loteamento, principalmente o DEMHAB e a Fundação de Assistência Social e Cidadania (FASC), que em muitas campanhas eleitorais os candidatos visitaram a Vila pedindo votos e prometendo melhorias nas condições de vida, que já foram solicitados a participar de associação de moradores, conselhos municipais, cooperativas de reciclagem ao longo dos anos e a única mudança que ocorreu em todo este período foi a construção do Loteamento (por causa do incêndio de 2005), logo, a falta de liderança e uma certa apatia quanto a participar mais ativamente nas decisões que afetam o Loteamento como um todo e a descrença numa ação mais efetiva da municipalidade se justifica.

A próxima unidade de registro que ficou evidente durante as entrevistas, é a pouca valorização da casa/habitação. A primeira pergunta feita a estas pessoas na entrevista era sobre a condição de vida na Vila dos Papeleiros. Todos responderam que era bom viver na Vila, apesar de todas as carências que existiam. Perguntados sobre o que consideravam ruim naqueles tempos, nenhum deles respondeu, em um primeiro momento, que era a casa/habitação. O primeiro item enumerado foi a lama, presente em toda Vila e que fazia com que os carrinhos atolassem com frequência: "Tinha barro até as canela". O segundo item mais citado pelos entrevistados foi a quantidade de ratos que dividiam o espaço e os alimentos com os moradores: "Tinha muito rato". A casa só é lembrada quando perguntamos a respeito dela, de como eram suas condições.

Quando perguntados sobre as condições de moradia no Loteamento, da mesma forma, a casa não aparece nas respostas como o item mais importante. Ter um endereço com nome de rua, número de casa e Código de Endereçamento Postal (CEP) é, na visão dos entrevistados, o mais importante. Na sequência, é citado o fim da lama (barro), água encanada, luz e só depois destes itens a casa é referenciada. A incidência de ratos nas moradias continua a existir (em menor número) considerando-se o tipo de atividade que eles desenvolvem - reciclagem de materiais usando suas casas como área de triagem e depósito. Considerando suas necessidades imediatas, é compreensível que a habitação não tenha 0 papel principal em suas observações sobre a Vila e o Loteamento. A lama acumulada nos caminhos da Vila, que impedia ou dificultava sobremaneira o ir e vir dos carrinhos de coleta, seu ganha-pão diário, e a quantidade de ratos que infestavam os barracos

Para0nde!?, Porto Alegre, v.13, n.1, p.111-131, 2020. http://seer.ufrgs.br/paraonde 
feitos de madeira, papelão ou qualquer outro material disponível, eram suas preocupações mais prementes.

Outro fato importante é que praticamente todas as casas foram ou estão sendo modificadas. A quantidade de pessoas morando na mesma casa induz à que se façam adaptações para comportar 10, 11 ou até 14 pessoas em uma área construída de $42 \mathrm{~m}^{2}$. Usa-se todo o espaço disponível para construir novos cômodos na casa. O pequeno pátio em frente à casa transforma-se em sala, o pátio nos fundos transforma-se em quarto, tudo isso sem qualquer tipo de fiscalização (Estado ausente).

Durante mais de 15 anos alguns destes moradores viveram em subabitações, barracos com um único cômodo sem banheiro (muitos usavam baldes como sanitário), sua preocupação imediata era com a sua sobrevivência seguida da sobrevivência dos filhos, a busca diária por recicláveis e a manutenção do carrinho (possibilidade de obter renda), a casa tinha uma importância secundária, o entendimento da importância ou não da casa foi transposta para as novas residências a partir de 2006 com a construção do Loteamento.

Assim, as transformações espaciais ocorridas ao longo do tempo no Loteamento, e que dizem respeito à forma como os moradores se relacionam com a casa, fazem com que a sociedade em geral (externa ao Loteamento) os veja como responsáveis por um processo de degradação das habitações.

Por fim, mas não menos importante está a presença do tráfico de drogas. Assunto delicado, porém, fundamental para o entendimento dos processos espaciais pelos quais passou e passa o Loteamento. Das entrevistas feitas para a pesquisa, somente 01 pessoa falou abertamente sobre o tráfico. Existe uma espécie de temor velado em falar deste assunto entre os moradores. Quando perguntados sobre o que elas consideram ruim no Loteamento, grande parte das respostas era: "tem umas coisa aí"; somente quando estimulados revelam que o tráfico incomoda: "Eles fazem a deles e eu faço a minha"; "Eles lá e eu aqui".

No ano de 2017, duas grandes operações policiais foram feitas no Loteamento para combater o tráfico: no dia 25 de maio e no dia 25 de julho. Nestas operações, a polícia revistou algumas casas na busca por drogas e armas, efetuando a prisão de traficantes que atuam no Loteamento. Alguns dos moradores entrevistados têm seus familiares envolvidos no tráfico, o que faz com que a cada operação policial suas casas sejam revistadas, de modo geral, de forma truculenta. Alguns deles nos revelaram que "nem tranco mais o portão, quando eles chega, quebra tudo, então não tranco mais".

Quando perguntados sobre o que pensam sobre estas operações da polícia, revelam que: "pra nóis é bom, a gente vive oprimido por esta gente". De outro lado, argumentam que os policiais tratam todos como se fossem bandidos nas revistas que fazem quando abordam pessoas nas ruas do Loteamento: "Se o teu celular é bom, eles leva, se é ruim eles atira no chão".

Existe uma tensão permanente, seja pelo traficante que impõe certas condições aos moradores (o silêncio), seja pelas autoridades policiais que

ParaOnde!?, Porto Alegre, v.13, n.1, p.111-131, 2020. http://seer.ufrgs.br/paraonde 
quando entram no Loteamento colocam todos em uma mesma classe: bandidos. Além daqueles que moram no Loteamento e são usuários ou trabalham para o tráfico, existem ainda os frequentadores eventuais, que circulam pelo Loteamento para comprar a droga. São pessoas em situação de rua que vivem nas calçadas próximas dos pontos de venda, morando em barracas de lona e circulando diariamente pelas ruas do Loteamento.

Deste modo, entendemos que o tráfico de drogas que poderia ser apontado como um efeito colateral da desorganização presente no Loteamento é, na verdade, um facilitador desta desorganização, pois se aproveita dela para a manutenção de seus negócios ilícitos. Nas palavras de um entrevistado: "O lixo tem uma função, ele não está ali à toa", referindo-se ao lixo acumulado nas ruas e calçadas do Loteamento.

Quando analisamos estas cinco características, que no seu conjunto formam um mosaico da realidade existente no Loteamento - evidenciando práticas espaciais que configuram e reconfiguram o espaço ao longo do tempo podemos apontar para uma condição de dualidade entre permanência e mudança, dependendo da perspectiva do sujeito ou observador. Esta condição indica que, ao se olhar superficialmente para este espaço, não enxergamos alterações significativas ao longo dos anos, mas apenas a permanência da situação de enorme carência.

A transformação do espaço na área onde atualmente se encontra o Loteamento Santa Terezinha é fruto das práticas espaciais usadas pelos moradores da Ponte, da Vila, do atual Loteamento, bem como por parte do Estado (na instância municipal).

Os moradores da Ponte/Vila eram, na sua gênese, produtores do espaço, construindo suas habitações na medida do possível com os materiais disponíveis sem qualquer intervenção do Estado, produzindo seu próprio espaço. A partir do momento em que o Estado intervém, propõe o projeto de construção do loteamento com habitações unifamiliares, arruamento, passeio público, áreas de lazer e convívio social, ele torna-se um agente efetivo de transformação do espaço impondo "de cima para baixo" sua concepção de loteamento popular e habitação. Os moradores têm que se adaptar ao modelo imposto e num primeiro momento isso de fato acontece, no entanto, com o passar dos anos cada morador vai otimizando sua casa para atender às suas necessidades (seja de espaço físico para a moradia, seja como depósito de materiais recicláveis).

No início dos anos de 1980 a área não tinha uso aparente, a partir da chegada de pessoas dos mais diversos locais do estado e mesmo da capital engendra-se um processo de ocupação que por consequência gera uma estrutura que possui uma forma própria e têm uma função. A estrutura (orgânica com apenas uma via de acesso) e a forma das subabitações (feitas de restos de madeira ou qualquer outro material disponível) e que tem por função a moradia e o armazenamento dos materiais recicláveis. Quando ocorre o incêndio, em 2005, e a prefeitura inicia o projeto de construção do Loteamento, produz-se nova estrutura, começa-se do zero e constroem-se novas habitações a partir de um modelo estabelecido pelo DEMHAB, como

ParaOnde!?, Porto Alegre, v.13, n.1, p.111-131, 2020. http://seer.ufrgs.br/paraonde 
consequência desta nova estrutura temos inicialmente uma nova forma, no entanto, função e processos permanecem os mesmos ao longo dos onze anos de existência desta nova forma, o Loteamento. Como estes moradores continuam a reproduzir práticas sociais e espaciais, estas casas começam a tomar a forma que as suas necessidades impõem (mais cômodos para abrigar os filhos, netos, noras, genros, agregados e materiais recicláveis).

Este processo de formação da Vila/Ponte evidencia uma refuncionalização do espaço até então subutilizado que se transforma em lugar de moradia e trabalho simultaneamente. Os moradores do Loteamento Santa Terezinha, pelas suas condições de extrema carência, constituíram o que se pode chamar de circuito econômico alternativo na medida em que, de forma autônoma, buscam possibilidades de coleta dos materiais recicláveis nos mais diversos lugares da cidade e ainda compradores para estes materiais (o que paga melhor), no que Santos (2008) ${ }^{1}$ denomina de circuito inferior da economia urbana.

Esta prática no Loteamento é frágil por conta do que observamos com as visitas que fizemos para realizar as entrevistas. A falta de liderança impede 0 fortalecimento de uma rede espacial com vistas a reivindicações, já que ela existe, mas é instável, volúvel. Além disso, as parcerias firmadas para apoiar socialmente os moradores, são abandonadas quando ocorre um evento como a operação policial citada anteriormente e veiculada na mídia atribuindo ao Loteamento à condição de zona de tráfico e uso de drogas, uma vez que estes apoiadores não querem ajudar supostos traficantes e usuários.

Não obstante, as entrevistas com agentes externos revelam um otimismo quanto às melhorias nas condições de vida dos moradores desde a Vila dos Papeleiros até o momento atual, mas estas mudanças só são percebidas pelos que vivem o cotidiano do Loteamento, ou seja, o espaço vivido, que nas palavras de Henri Lefebvre, é o espaço de representação, "[...] o espaço vivido através das imagens e símbolos que os acompanham, portanto, o espaço dos 'habitantes', dos 'usuários' [...]. Trata-se do espaço dominado, portanto, suportado, que a imaginação tenta modificar e apropriar" (LEFEBVRE, 2000, p. 66). Elas são graduais e muito lentas, imperceptíveis àqueles que só veem o Loteamento através da janela do ônibus, trem ou carro, ou do que é veiculado nos meios de comunicação, confirmando aquilo que estamos discutindo: a condição de permanência. Nada mudou, tudo permanece igual como há trinta anos, é o espaço percebido. De acordo com Lefebvre, o espaço percebido é uma associação estreita entre "a realidade cotidiana (o emprego do tempo) e a realidade urbana (os percursos e redes ligando os lugares do trabalho, da vida "privada", dos lazeres)" (LEFEBVRE, 2000, p.65), constituindo o que ele denomina prática espacial.

Nas quatro entrevistas feitas com agentes externos (SASE, Creche, Centro de Saúde e Paróquia), aparece em todas as respostas a afirmação da condição de mudança. Os entrevistados são otimistas quanto às melhorias nas condições de vida dos moradores desde a Vila dos Papeleiros até o momento atual, mas alertam para o fato de que o Loteamento tem apenas onze anos de existência. Este trabalho de mudança exige um tempo maior para se efetivar,

ParaOnde!?, Porto Alegre, v.13, n.1, p.111-131, 2020. http://seer.ufrgs.br/paraonde 
principalmente em relação às crianças, já que a maioria delas tem que aprender as coisas mais básicas como comer usando talheres, fazer as refeições sentadas na mesa, usar corretamente os equipamentos dos sanitários e assim por diante.

A reportagem do jornal Zero Hora do dia 01 de março de 2017 tem o seguinte título: "Esta rua poderia ser a mais bonita da cidade. Saiba por que não é”. A matéria diz respeito à rua Paraíba onde estão localizadas a Cooperativa Mãos Unidas e a Associação de Reciclagem Ecológica da Vila dos Papeleiros (AREVIPA), que pela natureza de seu trabalho atrai ratos e insetos que infestam as ruas e as casas dos moradores da rua, além do lixo espalhado pelas calçadas, a prostituição e o uso de drogas recorrente no local.

Conhecida por abrigar um casario antigo (Vila dos Ferroviários), tombado pelo Instituto do Patrimônio Histórico e Artístico Nacional (IPHAN) e um túnel verde de árvores centenárias, a rua Paraíba e seu conteúdo social representado por seus moradores sofrem, segundo os entrevistados pela reportagem, com a condição atual da área e citam os dois centros de triagem de resíduos sólidos como principais responsáveis pela degradação da rua que, segundo o título da reportagem, poderia concorrer em condições de igualdade com a rua Gonçalo de Carvalho conhecida como a rua mais bonita da capital, não fosse por estes "problemas" citados. São dois exemplos de como é apresentado pela mídia o morador do Loteamento e o trabalho que ele desenvolve, que de modo geral é considerado estigmatizado.

Apesar das mudanças apontadas e do otimismo manifesto por todos os agentes externos entrevistados, quando perguntamos a eles quantos jovens poderiam citar que tiveram um destino diferente daquele noticiado nos jornais e na televisão, não conseguiram nominar, de pronto, duas pessoas. Cada um citou apenas um nome, o que nos permite concluir que não é no espaço de uma geração (em torno de 25 anos) que poderemos observar uma mudança consistente de fato.

\section{Considerações Finais}

Ao chegar à parte final deste trabalho faz-se necessário retomar o que até aqui foi exposto sob pena de que estes tópicos pareçam partes dispersas, sem conexão uns com os outros. Antes, porém, é necessário sintetizar um fato que se apresentou durante as entrevistas e que possui dois aspectos distintos, porém, complementares e que compõem a realidade do Loteamento. Um dos aspectos é o discurso de que eles são pobres, carentes e precisam de ajuda do Estado, da paróquia e de quem se dispuser a ajudar, uma espécie de "coitadismo" repetido por grande parte dos entrevistados (um discurso apropriado pelos moradores, pois é ouvido por eles desde a formação da Vila/Ponte através dos assistentes sociais, voluntários e da mídia), O outro aspecto que chamou nossa atenção e nos parece relevante externar é a baixa autoestima destes moradores entrevistados, uma espécie de vergonha de estar naquela situação (de extrema carência) e isso ficou evidente quando nos recebiam em suas casas onde grande parte do mobiliário, utensílios domésticos, roupas e alimentos é fruto de doação. Por isso, a importância de

ParaOnde!?, Porto Alegre, v.13, n.1, p.111-131, 2020. http://seer.ufrgs.br/paraonde 
revelar estes aspectos e esclarecer que nossa análise, do universo estudado, levou em consideração tais fatos.

Quando fazemos uma análise integrada, ou seja, usando os dados do perfil socioeconômico, os dados qualitativos das entrevistas, o contexto da cidade de Porto Alegre no momento atual, o histórico do município com relação às populações de baixa renda (abandono, remoções forçadas) e o entendimento de que o Loteamento, embora seja analisado como um recorte espacial da cidade, não está isolado desta e sofre as consequências das diversas ações propostas pelo poder público municipal, temos um quadro que explica (ainda que temporariamente) as unidades de registro que foram apontadas em nossa interpretação dos dados.

Estas pessoas, sem o devido trabalho de acompanhamento do Estado no que diz respeito aos usos e funcionalidades das novas residências, acabam por total desconhecimento da nova realidade, fazendo mau uso destes equipamentos o que redunda uma vida útil reduzida, manutenção inadequada ou inexistente e adaptações temerárias. Todas as casas do Loteamento passaram ou estão passando por alterações em sua estrutura para comportar o número de pessoas que ali moram. Em nosso trabalho de campo visitamos trinta residências, algumas delas com dez ou mais pessoas vivendo no mesmo espaço, o que sugere que possibilidades de adaptações têm que ser projetadas e viabilizadas aos moradores, dentro do possível.

Toda esta dinâmica de transformação do espaço do Loteamento produzido por estas práticas sócio-espaciais - posto que as relações sociais e o espaço são inseparáveis ainda que não se confundam, nas palavras de Souza (2013) alterações nos padrões das casas, uso das casas para triagem e depósito, descarte de resíduos nas ruas e calçadas do Loteamento, locação de cômodos construídos de forma irregular, dá ao Loteamento o aspecto de aparente desorganização e desleixo.

Os moradores replicam o discurso de que o Estado (prefeitura municipal) Ihes abandonou à própria sorte aparecendo no Loteamento apenas para cobrar-lhes alguma coisa, esquecem que a presença do Estado é constante através da Secretaria de Saúde e do DMLU, que diariamente faz limpeza na parte duplicada da rua Voluntários da Pátria, em frente ao Loteamento. A atuação do Estado que sempre é lembrada é a da Brigada Militar nas operações de combate ao tráfico de drogas, porte ilegal de armas e munições, roubos e furtos que quando acontecem são amplamente divulgadas pela mídia.

Esta condição de desordem aparente, citada anteriormente, é aproveitada pelo tráfico de drogas para estabelecer seu mercado de vendas a varejo. Nenhum dos moradores entrevistados na pesquisa apontou este fato como um problema do Loteamento, é uma questão velada, que remete ao silêncio por medo de represálias e porque alguns dos entrevistados têm seus familiares envolvidos direta ou indiretamente no tráfico. O que se denota através das entrevistas e conversas informais quando se fala do tráfico é uma certa "naturalização" deste fenômeno, ou seja, esta prática sempre existiu, desde a Vila/Ponte, continua existindo agora e continuará existindo, portanto, é natural que aconteça, eles apenas adaptam-se a isso.

ParaOnde!?, Porto Alegre, v.13, n.1, p.111-131, 2020. http://seer.ufrgs.br/paraonde 
Mesmo considerando todas estas condições adversas dissertadas anteriormente (falta de liderança, aversão a cooperativas, pouca importância com a casa, ausência do Estado e tráfico de drogas), todos aqueles que trabalham no Loteamento seja de forma voluntária ou não, são otimistas quanto ao futuro desta população. A aposta é nas crianças que frequentam a creche (crianças de 0 a 6 anos) e os que frequentam o SASE no turno inverso ao da escola buscando, através da educação, ampliar os horizontes destas crianças, mostrando que é possível uma vida diferente daquela que eles conhecem.

Compartilhamos deste otimismo, uma vez que, com relação à educação de crianças e jovens, parece-nos o caminho para a transformação das relações sociais presentes no Loteamento e para a emancipação dos sujeitos, para que sejam protagonistas de suas vidas, façam autonomamente suas escolhas e não sejam apenas coadjuvantes nos processos decisórios que os afetam, que não fiquem passivamente aguardando as benesses do Estado provedor e de ações de caridade.

Todavia, não temos o mesmo otimismo com relação à permanência do grupo de moradores do Loteamento no local onde se encontra atualmente. Considerando que o desenvolvimento/crescimento das cidades se dá em ciclos de valorização, desvalorização e revalorização; considerando que a área onde se localiza o Loteamento está desvalorizada; considerando que existem projetos de revalorização e de refuncionalização daquela área; considerando que a relação de vizinhança do entorno com o Loteamento não é, na sua maioria amistosa, de acordo com as entrevistas feitas com os moradores; considerando que a mídia apresenta o Loteamento como uma zona de tráfico e uso de drogas, receptação de furtos e roubos, prostituição e afluência de usuários de crack, com lixo acumulado nas ruas e calçadas; considerando o histórico da cidade de Porto Alegre no que diz respeito a medidas higienistas e remoções forçadas de populações de baixa renda; considerando que o capital financeiro e imobiliário influencia fortemente o Estado impondo sua lógica sobre o planejamento urbano via alterações no Plano Diretor feitas à revelia da população, nos parece lícito afirmar que a medida em que a revalorização da região do Quarto Distrito (onde está inserido o Loteamento) se concretizar, estas pessoas poderão ser removidas dali e realocadas em outra parte da cidade.

Neste sentido, encaminhamos nossas considerações finais reiterando que esta é nossa posição a partir do que foi possível vivenciar nos trabalhos de campo e nas pesquisas bibliográficas feitas para embasar nosso trabalho. Torna-se necessário enfatizar que este processo de possível remoção do Loteamento não é algo que ocorrerá em curto prazo pois a dinâmica da transformação da cidade é gradual e tem seu próprio tempo determinado pela lógica de reprodução do capital.

\section{Notas}

1 - A teoria dos dois circuitos da economia urbana foi proposta por Milton Santos em livro denominado "O espaço dividido: os dois circuitos da economia urbana dos países subdesenvolvidos", cuja primeira edição é de 1979.

ParaOnde!?, Porto Alegre, v.13, n.1, p.111-131, 2020. http://seer.ufrgs.br/paraonde 


\section{Referências}

BARDIN, Laurence. Análise de Conteúdo. Lisboa: Edições 70, 1979.

CÂMARA, R. H. Análise de conteúdo: da teoria à prática em pesquisas sociais aplicadas às organizações. Belo Horizonte, MG: Revista Interinstitucional de Psicologia, Vol. 6 (2), jul-dez de 2013, 179-191.

CARLOS, Ana Fani Alessandri. Da "organização" à "produção" do espaço no movimento do pensamento geográfico. In: CARLOS, Ana Fani Alessandri; SOUZA, Marcelo Lopes de; SPOSITO, Maria Encarnação Beltrão (org.). A produção do espaço urbano: agentes e processos, escalas e desafios. São Paulo: Contexto, 2011.

CHIZZOTTI, Antonio. Pesquisa qualitativa em ciências humanas e sociais. Petrópolis, RJ: Vozes, 2006.

CORRÊA, Roberto Lobato. O espaço urbano. São Paulo: Ática, 2005. 94 p.

CORRÊA, Roberto Lobato. Espaço: um conceito-chave da Geografia. In: CASTRO, Iná Elias de; COSTA GOMES, Paulo César da; CORRÊA, Roberto Lobato (org.). Geografia: conceitos e temas. Rio de Janeiro: Bertrand Brasil, 2012. 352p.

ESTA rua poderia ser a mais bonita da cidade. Saiba por que não é. Zero Hora, Porto Alegre, 01 mar. 2017. Questão urbana. Disponível em: https://gauchazh.clicrbs.com.br/porto-alegre/noticia/2017/03/esta-rua-poderiaser-a-mais-bonita-da-cidade-saiba-por-que-nao-e-9732018.html. Acesso em: 08 mar. 2019.

GIL, Antônio Carlos. Métodos e técnicas de pesquisa social. São Paulo: Atlas, 1989.

LEFEBVRE, Henri. A produção do espaço. Trad. Doralice Barros Pereira e Sérgio Martins (do original: La production de l'espace. 4e éd. Paris: Éditions Anthropos, 2000). Primeira versão: início - fev.2006.

MORAES, Aldovan de Oliveira. Duas ou três coisas a respeito de regularização fundiária. - 2 ed. - Prefeitura Municipal de Porto Alegre. Departamento Municipal de Habitação. Porto Alegre, 2007.

OPERAÇÃO termina com oito presos na Vila Santa Terezinha, em Porto Alegre. Correio do Povo, Porto Alegre, 25 jul. 2017. Notícias. Polícia. Disponível em: http://www.correiodopovo.com.br/Noticias/Policia/2017/07/623889/Operacaotermina-com-oito-presos-na-Vila-Santa-Terezinha,-em-Porto-Alegre. Acesso em: 23 mar. 2019.

POLíCIA deflagra operação contra "rodízio" de facções em vila de Porto Alegre. Correio do Povo, Porto Alegre, 25 mai. 2017. Notícias. Polícia. Disponível em: http://www.correiodopovo.com.br/Noticias/Pol\%C3\%ADcia/2017/5/618700/Polic ia-deflagra-operacao-contra-rodizio-de-faccoes-em-vila-de-Porto-Alegre.

Acesso em: 24 mar. 2019. 
POLICIAIS realizam operação na região central de Porto Alegre. Correio do Povo, Porto Alegre, 25 jul. 2107. Notícias. Polícia. Disponível em: http://www.correiodopovo.com.br/Noticias/Policia/2017/07/623862/Policiais-

realizam-operacao-na-regiao-central-de-Porto-Alegre. Acesso em: 23 mar. 2019.

PREFEITURA MUNICIPAL DE PORTO ALEGRE. Loteamento Santa Terezinha ganhará mais 30 moradias. Diário Oficial de Porto Alegre, Porto Alegre, 18 de out. 2007, ed. 3133, p. 1. Disponível em: http://proweb.procempa.com.br/pmpa/prefpoa/dopa/usu_doc/18outubro07.pdf. Acesso em: 24 mar. 2019.

SANTOS, Milton. Espaço e método. São Paulo: Nobel, 1985.

SANTOS, Milton. O espaço dividido: os dois circuitos da economia urbana dos países subdesenvolvidos. Trad. Myrna T. Rego Viana. - $2^{\mathrm{a}}$ ed., $1^{\mathrm{a}}$ reimp. São Paulo: Editora da Universidade de São Paulo, 2008.

SCHMID, Christian. A teoria da produção do espaço de Henri Lefebvre: em direção a uma dialética tridimensional. GEOUSP: Espaço e Tempo (Online), São Paulo, n. 32, p. 89-109, dec. 2012. ISSN 2179-0892. Disponível em: http://www.revistas.usp.br/geousp/article/view/74284. Acesso em: 09 set. 2018.

SOUZA, Marcelo Lopes de. Os conceitos fundamentais da pesquisa sócioespacial. - 1 ed. - Rio de Janeiro: Bertrand Brasil, 2013. 320p. 